take a single instance, Magdalen College spends more than $500 \mathrm{cl}$. a year upon science professorships, fellowships and scholarships, or a seventh part of its net revenue, and of the last twelve fellowships it has awarded, six have been for research. Also it keeps up a very efficient private laboratory, as, indeed, do five other colleges in the university.

Oxford, January 9.

H. M. VERNON.

I THINk that others may interpret the footnote as $\mathrm{Mr}$. Vernon does, and it is therefore my intention to express myself more clearly when the address is republished. Surely all Oxford science men know what I meant to say, and if so, they must know how difficult it is to say it without making two or three particular references. It is evident from other parts of my address that I certainly did not mean that most of the Oxford science professors neglect research. On the contrary, I know that the majority of them perform their duties well, including duties as to research, and they do this in an antipathetic atmosphere such as science professors elsewhere know nothing of. If I had the inclination to punish a scientific man and the power, I would appoint him to an Oxford science professorship.

Some of the most distinguished workers were listening to my address, and I know that they were not much annoyed when I expressed my opinion that, relatively to the position and wealth of Oxford, there is very little being done. We know the names of the Oxford men who are doing good research work in Oxford and elsewhere, and surely $\mathrm{Mr}$. Vernon will not say that they form one-tenth of one per cent. of the number of living men who have been educated at Oxford. But I am not concerned with the easy standard which he is satisfied to apply. I was expressing what is a very general opinion, and one that is certainly my own. Also in saying that Oxford fears and hates natural science I was expressing a very general opinion. It is ridiculed by Mr. Vernon, but he does not disprove it when he tells how Oxford trifles with science by the establishment of what are called science scholarships and fellowships and starved little laboratories.

Public opinion has been burked for many years by this grotesque fooling. Add to this that the majority of the dons throw ridicule upon natural science studies and create an atmosphere in which it is nearly as difficult for a man to do scientific work as it is for a mouse to live in an atmosphere of carbonic acid. An earnest student of natural science swims in a sea of troubles, and the university authorities in their love for him ornament him with a millstone of compulsory Greek as neck ornament. Surely this is something worse than trifling; it is torture. The torture is not so exquisite as what is applied to natural science in schools which are under Oxford influence, but it serves its purpose.

John PERry.

\section{An Undescribed Rudimentary Gill-plume in the Cray-} fish.

I sHould be glad if you would allow me to place on record the discovery, by Miss Margery Moseley (daughter of my old friend, the late Prof. H. N. Moseley, of Oxford), in specimens of the common cray-fish (Astacus fluviatilis), of a pair of minute gill-plumes (right and left), belonging apparently to the somite of the first pair of maxillipedes. Miss Moseley discovered these new minute gill-plumes, independently, in the course of dissection of a series of "types" in the department of comparative anatomy at Oxford. Finding no description of them in the text-books, and that they were not recognised or admitted by the authorities, she sent her notes and drawings on the subject to me. The discovery has been confirmed at my request by Dr. Calman, who is engaged in work on the Crustacea at the Natural History Museum, and he expresses his astonishment (in a letter to me) that so important and (when once noted) so obvious an organ can have been overlooked by the many students who have carefully examined the crayfish since Huxley made it one of his "types," and published his researches on the gills of the astacoid Crustacea.

The discovery is interesting, not only as a fact in the morphology of Crustacea, but as being a novelty in a subject treated with special attention by so skilled an observer as Huxley, and minutely examined by thousands of students and teachers during the last twenty years. Miss Moseley is preparing a description and drawings of the new gillplumes for immediate publication.

January 15 .

\section{E. Ray Lankester.}

\section{A Theory of the Cause of Atmospheric Electricity.}

THE idea that the sun sends out a large amount of Becquerel rays has found considerable support in the scientific world, and has been used to explain a number of difficulties connected with cosmical physics, for example, the source of the sun's energy and comets' tails. There is still another old standing difficulty which it appears to be able to solve, viz. the permanent maintenance of the electrical field in the lower regions of the earth's atmosphere. If we take for granted that the sun continually emits Becquerel rays consisting of positive and negative electrons, one would expect the following to be the consequence. Some of the electrons which reach the earth's atmosphere will be absorbed-probably mainly by the water vapour and dust in the lower atmosphere-but according to Rutherford's experiments more positive than negative; thus we may expect a greater number of negative electrons to reach the surface, a corresponding number of positive electrons being held back by the air. We at once see a cause for the positive charge of the air and the corresponding negative charge on the surface. If there were no "dissipation " the result would be a continual charging up of the atmosphere or an ever increasing potential gradient above the earth's surface; but there is dissipation, and it counterbalances the tendency of the electrical field to increase. If we had a constant dissipation the result would be a maximum potential gradient in the daytime and a minimum in the night, for we must assume that more electrons reach the atmosphere in the day than in the night. But we know from Elster and Geitel's measurements that the dissipation reaches a maximum at midday; this will tend to reduce the maximum of potential gradient which would otherwise be reached about that time. This consideration agrees entirely with the fact for Exner has described the daily variation of the potential gradient as " a simple daily period, distorted by a midday depression." With the fairly constant daily period of the entrance of electrons into the atmosphere, the main determining factor of the potential gradient will be the dissipation; thus we find a maximum potential gradient in the winter with a corresponding minimum dissipation. The relation between potential gradient and dissipation has been thoroughly investigated by Elster and Geitel, and they have found experimentally that that which tends to reduce the dissipation tends to increase the potential gradient," which is just what one would expect from the theory. This theory appears to me to be able to account for a great many more of the problems of atmospheric electricity, but the above will show the general idea. George Simpson.

\section{Projection of Imitation Spinthariscope Appearance.}

Witu reference to Sir Oliver Lodge's letter in NatURE of last week (p. 247), might I venture to say that I exhibited to a large audience the nature of the effect seen in a spinthariscope in a lecture which I gave on radio-activity at the Cavendish Laboratory last term? My plan is somewhat similar to that suggested by one of Sir Oliver Lodge's sons, and consists of two black discs rotating in opposite directions in a mechanical slide. The discs have a large number of transparent spots, so that whenever two of these coincide a flash is produced on the screen. The resultant effect is the same as that seen in the spinthariscope. The coincidences can be arranged so as to be most numerous near the centre.

J. B. B.

\section{The Diminishing Size of the New Bishop's Ring around the Sun.}

In addition to the notes recently given in NATURE by Prof. Forel, Mr. Rotch and Mr. Backhouse concerning the new Bishop's Ring, I should like to direct attention to the steadily diminishing size of this ring.

Mr. Backhouse says in vol. lxvii. (p. 174) that the middle of this reddish ring in the summer of 1902 was $70^{\circ}$ from the sun, but on December $2 \mathrm{I}$ it was only $40^{\circ}$ from the sun. 